\title{
COORDENADORES DE COMUNIDADES DE REPOSITÓRIOS INSTITUCIONAIS: O CASO DO REPOSITÓRIUM ${ }^{1}$
}

\author{
COORDINATORS OF INSTITUTIONAL REPOSITORIES COMMUNITIES: \\ THE REPOSITÓRIUM CASE
}

Flávia Garcia Rosa

Doutoranda do Programa de Pós-graduação Multidiscplinar em Cultura e Sociedade da Facom $\backslash$ UFBA

Universidade Federal da Bahia

flaviagr@ufba.br

Maria João Gomes

Doutora em Educação - Tecnologia Educativa

Universidade do Minho

mjgomes@ie.uminho.pt

\begin{abstract}
RESUMO
O Movimento do Acesso Livre - Open Access Movement (OAM) - foi estimulado por dois eventos importantes: a evolução das TIC, processo facilitador da disseminação e acessibilidade à informação, e os elevados custos das publicações científicas impressas, face a contextos de maiores constrangimentos financeiros da instituições de ensino superior e de investigação. Os Repositórios Institucionais (RI) são um dos elementos fundamentais do OAM e encontram-se em processo de expansão. Este texto reporta-se a um estudo focado nos coordenadores de comunidades do repositório institucional da Universidade do Minho tendo por objectivos a identificação do perfil dos coordenadores e a identificação de práticas de estímulo ao depósito ao nível das diferentes comunidades. A metodologia de investigação adoptada consistiu num levantamento (survey) através de um questionário online. Os dados recolhidos apontam para o reconhecimento, por parte dos coordenadores, das vantagens associadas ao depósito em RI, mas identificam também casos de desconhecimento do OAM e de baixo nível de auto-arquivamento por parte de alguns coordenadores de comunidades. São identificadas como principais iniciativas ao nível das políticas de estímulo ao depósito, por parte das várias comunidades, a "obrigatoriedade do depósito" e práticas de "apoio mediado". A análise dos dados recolhidos conduziu-nos a um conjunto de reflexões que entendemos poderem ser aplicadas ao caso do RepositóriUM, mas também constituir uma orientação para outros RI em desenvolvimento.
\end{abstract}

PALAVRAS-CHAVE: Repositórios institucionais. RepositóriUM. Acesso livre. Publicações académicas. Publicações científicas.

\section{INTRODUÇÃO}

Compete aos investigadores o registo dos novos saberes, fruto das teorias e suas relações com o mundo real, através de métodos científicos de refutação ou confirmação de hipóteses e teorias (POPPER, 1972, 1971). É dessa forma que a ciência avança numa dinâmica que tem

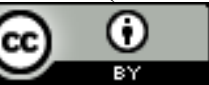
DOI 10.5007/1518-2924.2010v15nesp2p100

\footnotetext{
${ }^{1}$ A realização deste estudo foi apoiado pela CAPES - Brasil e pelo CIEd-UM - Portugal. As autoras agradecem a Eloy Rodrigues, Director dos SDUM e Ricardo Saraiva a disponibilização de muitos dos dados referidos neste texto.

Enc. Bibli: R. Eletr. Bibliotecon. Ci. Inf., Florianópolis, n. esp., 2º sem. 2010. ISSNe 1518-2924.
} 
na comunicação científica o seu ciclo, no qual se inclui o registo, armazenamento, recuperação e disseminação desses saberes e resultados das investigações para um público mais amplo.

A chegada da Internet, e particularmente a sua enorme expansão com o surgimento do WWW no início dos anos de 1990, modificou o ciclo da disseminação da comunicação científica. Uma mudança, sobretudo estrutural - ao nível do tempo e espaço - alterando o fluxo da informação (BARRETO, 1998). No processo da construção da ciência "[...] é fundamental um trabalho coletivo, em que pesquisadores e grupos de pesquisa trabalham sobre resultados já obtidos por seus pares, e têm como objetivo acrescentar um tijolo a mais num vasto edifício." (MARCONDES, SAYÃO, 2002, p. 44), suportado pelas tecnologias de informação e comunicação (TIC) que contribuem e facilitam o processo de troca de ideias, a discussão de resultados de investigação em tempo real e a colaboração entre investigadores.

Um dos problemas associados à disseminação do conhecimento científico decorre do elevado custo de muitas publicações periódicas de carácter científico, frequentemente na dependência de interesses editoriais e comerciais que raramente revertem em prol dos autores ou das instituições em que os mesmos estão filiados. Segundo Marcondes (2009, p. 91), "A maior parte dos títulos de periódicos acadêmicos é editada por um mercado protagonizado por oligopolistas, que assim, passaram a usufruir de ganhos."

A partir da década de 1970, e com maior ênfase nas décadas de 1980 e 1990, o crescente custo dos periódicos científicos e as crescentes restrições financeiras de muitas universidades e centros de investigação tornou o processo de aquisição de assinaturas por parte destas instituições cada vez mais difícil, dificultando o acesso às informações geradas no âmbito das diferentes disciplinas científicas, consequentemente aumentando os obstáculos ao desenvolvimento da ciência e ampliando a desigualdade de condições de acesso ao conhecimento por parte de diferentes países, instituições e investigadores. Esta, denominada por alguns autores de "crise dos periódicos acadêmicos" (MARCONDES, 2009; RODRIGUES et al., 2004, STUMPF, 1996), causou um enorme impacto no acesso ao conhecimento produzido nos meios académicos e científicos, com destaque particular nas bibliotecas ao nível dos países em desenvolvimento.

Foi a partir desses dois eventos, primeiro o aperfeiçoamento das TIC que facilitou a disseminação e acessibilidade da informação, e segundo, a criação de barreiras associados aos elevados valores cobrados por parte das grandes editoras que controlavam o mercado das publicações cientificas, que surgiu o Movimento do Acesso Livre - Open Access Movement $(\mathrm{OAM})$ - referente às publicações científicas. Este surge como "[...] uma forte reacção, de âmbito internacional, por parte de investigadores, académicos, bibliotecários e gestores de informação [...]"2 (JORGE, 2006, tradução nossa). Este movimento é definido pelo "uso de ferramentas, estratégias e metodologias que denotam um novo modelo de representar um igualmente novo processo de comunicação científica." (COSTA, 2006) e engloba questões como: software livre ou aberto; arquivos abertos; acesso aberto; e a ideia de eliminar a obrigatoriedade de cedência do copyright de artigos publicados permitindo aos autores a inserção da sua produção científica, sem restrições, em repositórios temáticos ou institucionais (LINCH, 2003), facilitando a sua disseminação de forma mais rápida, eficaz e gratuita. Segundo King (2010, p. 2, tradução nossa), “[...] o livre acesso a toda a literatura

\footnotetext{
2 “[...] una fuerte reacción por parte de investigadores, académicos, bibliotecarios y gestores de información en el ámbito internacional [...]"

Enc. Bibli: R. Eletr. Bibliotecon. Ci. Inf., Florianópolis, n. esp., $2^{\circ}$ sem. 2010. ISSNe 1518-2924.
} 
científica não tem apenas valor substancial para os investigadores financiados por órgãos federais enquanto leitores, mas também para outros cientistas, além de ser um ganho para a ciência e suas contribuições para economia e para a sociedade."

A adopção de Repositórios Institucionais tem crescido em todos os países, com ênfase nas universidades, graças ao contexto descrito anteriormente. Segundo Crow (2002, p. 16, tradução nossa), "[...] repositório institucional é um arquivo digital da produção intelectual criada pelos académicos, investigadores e alunos de uma instituição, e acessível a utilizadores finais, quer internos quer externos à instituição, com poucas ou nenhumas barreiras de acesso." 4

A Universidade do Minho (UM), situada em Braga, Portugal, participou desde 2001 em discussões em torno do Open Access Movement (OAM). Na sequência desse envolvimento, o projecto de criação e implantação do Repositório Institucional (RI) da UM - RepositóriUM ${ }^{5}$ - iniciou-se em maio de 2003, tendo recolhido desde o início o apoio e confiança da reitoria da Universidade, segundo Rodrigues (2010). Esse apoio e reconhecimento da relevância do projecto para a instituição revelou-se um factor essencial para o sucesso do mesmo, o qual, em Janeiro de 2010 completou seis anos de implantação e de funcionamento aberto a todas as comunidades, para além das comunidades piloto iniciais. À data de escrita deste texto, o Repositórium possui 35 comunidades activas, as quais se enquadram em diferentes unidades orgânicas (Departamentos e Centros de Investigação) da UM. Destas comunidades, duas estão directamente ligadas aos SDUM sendo uma delas destinada à disponibilização de teses e dissertações de mestrado e doutoramento.

A criação do RI da Universidade do Minho pode considerar-se um marco de relevo no processo de criação de RI em língua portuguesa, uma vez que foi o primeiro repositório deste tipo em Portugal e tem constituído um referencial ao desenvolvimento de outros repositórios, nomeadamente em Portugal e nos países de língua oficial portuguesa. Assim, considerou-se importante estudar, sob diferentes ângulos, o processo de implementação e disseminação do RI da Universidade do Minho, procurando aumentar o conhecimento disponível nesta área, de forma a que o mesmo possa vir a ser rentabilizado no processo de criação e desenvolvimento do RI de outras instituições. Neste texto apresenta-se um estudo levado a cabo entre Janeiro e Março de 2010, na Universidade do Minho, tendo como foco de análise os coordenadores das diferentes comunidades que constituem o RepositóriUM.

Optou-se por estruturar este texto iniciando-o com um enquadramento geral da problemática associada ao surgimento dos RI, a que acabamos de nos reportar nos parágrafos anteriores, prosseguindo com breve revisão de literatura na qual se focam aspectos relacionados com as políticas institucionais de estímulo e dinamização de comunidades de RI contemplando os aspectos da política da instituição para a coordenação das comunidades do RI do Minho. $\mathrm{O}$ artigo prossegue fazendo referência aos objetivos do estudo e apresentando o desenho da pesquisa apresentando os grupos de sujeitos envolvidos e os procedimentos e instrumentos de

3 “' $[. .$.$] 'free' access to all science literature not only has substantial value to federally funded researchers as$ readers, but also to other scientists as well which is a gain to science and its contribution to the economy and society."

$4[\ldots]$ an institutional repository is a digital archive of the intellectual product created by the faculty, research staff, and students of an institution and accessible to end users both within and outside of the institution, with few if any barriers to access.

$5 \mathrm{http}: / /$ repositorium.sdum.uminho.pt/ 
recolha de dados. Na última parte faz-se a apresentação e discussão dos dados recolhidos finalizando com as conclusões decorrentes dos mesmos, juntamente com um conjunto de recomendações passíveis de aplicação não só ao RI da UM, mas também a outros repositórios.

\section{DAS POLÍTICAS INSTITUCIONAIS À COORDENAÇÃO DAS COMUNIDADES DO REPOSITÓRIUM}

O processo de implementação e desenvolvimento de RI implica um processo de dinamização dos mesmos que assegure o seu crescimento, alargue a sua visibilidade quer interna à instituição, quer externa à mesma, e que promova a sua utilização, quer por parte dos potenciais depositantes, quer por parte dos utilizadores finais. Este processo, para ser bem sucedido, passa pela definição de políticas institucionais de diversa ordem e por opções organizacionais de diferente natureza.

Briceno et al (2009), com base na experiência de oito anos de funcionamento do Repositório Institucional SABER-ULA da Universidade dos Andes, em Mérida, Venezuela, referem que um dos factores que contribuiu para a promoção do livre acesso ao conhecimento produzido na instituição através do repositório, foram as políticas institucionais desenvolvidas que incentivaram os produtores de conhecimento a realizar o depósito no RI.

No que diz respeito à Universidade do Minho, a própria instituição criou mecanismos de estímulo através de instrumento normativo o RT- 6/2005, estabelecido pela Reitoria da UM, o qual reforçou a relevância e interesse das diferentes unidades orgânicas em aderir ao RI do UM, e através do qual a própria reitoria da Universidade alocava recursos financeiros adicionais às unidades orgânicas e centros da UM que aderissem ao depósito de documentos no RepositóriUM, sendo que os recursos seriam proporcionais aos depósitos realizados. Segundo Ferreira et al (2008, s/p), como resultado desta medida, "[...] de 1 de Janeiro a 31 de Dezembro 2005, foram depositados no RepositoriUM 2,813 documentos 8 [...]". Segundo os mesmos autores (Ferreira et al, 2008, s/p), em 2006 foi também disponibilizada uma verba adicional de 30,000 euros para ser distribuída de acordo com os mesmos princípios do ano anterior tendo como resultado que em 2006 foram depositados 1,885 documentos, 83\% dos quais através do auto-arquivamento por parte dos próprios autores, sendo os restantes (essencialmente teses e dissertações de mestrado e doutoramento) depositados pelos funcionários dos serviços de documentação.

Para além de iniciativas mais ou menos pontuais de incentivo ao depósito, a verdadeira força motriz de qualquer repositório são os seus potenciais depositantes, sendo por isso essencial que estes se encontrem informados sobre as potencialidades dos RI e as vantagens da sua utilização e se encontrem motivados para a participação no desenvolvimento dos mesmos. Para Dávila; Nunez; Sandia (2006, p. 7, tradução nossa):

A sustentabilidade e desenvolvimento de um RI baseia-se, principalmente, na sensibilização da comunidade académica para preservar e difundir sua produção intelectual mediante este tipo de plataforma. Não existe uma metodologia única e os mecanismos de alimentação da informação não são universais, uma vez que se fundamentam em esquemas culturais e costumes institucionais. ${ }^{6}$

6"La sustentabilidad y desarrollo de un RI se basa, principalmente, en el convencimiento de la comunidad académica para preservar y difundir su producción intelectual mediante este tipo de plataforma. No existe una Enc. Bibli: R. Eletr. Bibliotecon. Ci. Inf., Florianópolis, n. esp., 2º sem. 2010. ISSNe 1518-2924. 
Para se estimular os professores/investigadores é necessária a criação de mecanismos motivadores, sejam para a comunidade como um todo ou mesmo individuais (DÁVILA; NUNEZ; SANDIA 2006). É preciso que os membros de qualquer comunidade tenham em mente que os RI "[...] ao armazenar e expandir através do livre acesso a produção dos seus investigadores estão a contribuir para a valorização da sua produção científica.” (SOUSA; QUONIAM; TRIGO, 2008).

Assim, importa que nos processos de desenvolvimento dos RI sejam assegurados mecanismos de informação, formação e motivação dos membros das diferentes comunidades. É nossa convicção que a existência de um coordenador de cada comunidade de um RI pode ser um elemento importante no processo de dinamização e desenvolvimento da mesma. Foi tendo por base esta convicção que desenvolvemos um estudo centrado no perfil e actividades dos coordenadores das comunidades do repositório institucional da Universidade de Minho.

\section{ENQUADRAMENTO E OBJECTIVOS DO ESTUDO}

As políticas institucionais e os modelos de organização dos RI são diversificados e distintos de instituição para instituição. No caso da UM o modelo adoptado é bastante descentralizado, competindo às diferentes unidades orgânicas proporem aos SDUM - entidade que coordena a nível geral e que assegura as funcionalidades do RI - a criação de comunidades e das colecções dessas comunidades.

Na página web do RepositóriUM ${ }^{7}$ há um guia referente à criação de comunidades - Adesão de novas comunidades - onde constam as orientações necessárias para a implantação e funcionamento de uma comunidade. Nesse documento, são identificadas as responsabilidades, tarefas e direitos das comunidades, os quais estão sintetizados no (Quadro 2, a seguir):

metodología única y los mecanismos de alimentación de información no son universales, ya que se fundamentan en esquemas culturales y costumbres institucionales."

$7 \mathrm{http}: / /$ repositorium.sdum.uminho.pt/about/novacomunidade/index.htm 
Responsabilidades, tarefas e direitos associados às comunidades do RepositóriUM:

Respeitar as políticas relativas ao RepositóriUM e (in)formar os seus membros acerca dessas políticas.

Tomar as decisões relativas à definição de comunidades e colecções. Aprovar a criação ou eliminação de sub-comunidades.

Decidir acerca do processo de depósito (workflow) para cada colecção.

Personalizar interfaces para os conteúdos da comunidade.

Decidir a política relativa aos conteúdos/documento depositados (dentro das orientações

gerais do RepositóriUM).

Obter licença/direitos relativos a documentos cujo detentor dos direitos de autor não seja a Universidade do Minho ou o autor.

Realizar o depósito e descrição de documentos.

Decidir quem pode depositar documentos dentro da comunidade.

Limitar o acesso a conteúdos, ao nível de cada documento, apenas à Universidade do

Minho (poderão existir situações excepcionais de acesso ainda mais restrito) quando

necessário por razões de copyright, ou outras devidamente justificadas.

Informar os SDUM de alterações organizacionais que afectem o processo de depósito.

Quadro 1 - Responsabilidades, tarefas e direitos associados às comunidades do

RepositóriUM.

Fonte: Autores

Cada comunidade do RepositóriUM possui um coordenador, nomeado pela respectiva comunidade, o qual constitui o elo de ligação da comunidade com os SDUM, responsáveis gerais do RI. Note-se que as responsabilidades e tarefas atribuídas às comunidades não estão directamente alocadas aos seus coordenadores, existindo liberdade das comunidades na forma como se organizam e como concretizam a realização e o exercício dessas tarefas, responsabilidades e direitos. Sendo os coordenadores de comunidades os interlocutores directos das comunidades com os responsáveis do RI ao nível dos SDUM e, como referimos anteriormente, considerando que os coordenadores podem ser elementos importantes ao nível das respectivas comunidades, focamos este estudo no conhecimento do perfil e actividades dos coordenadores tendo em vista um conjunto de objectivos:

1) caracterizar em termos gerais o perfil dos coordenadores de comunidades do RepositóriUM e conhecer os seus conhecimentos sobre o OAM bem como as suas práticas enquanto depositantes ${ }^{8}$;

2) identificar medidas internas adotadas pela comunidade para incentivar os seus professores/investigadores a procederem ao depósito da sua produção académica e científica;

3) apresentar reflexões e sugestões que permitam repensar o perfil e as funções dos coordenadores das comunidades, quer ao nível do RI da UM quer ao nível de outros RI.

\footnotetext{
${ }^{8}$ Os coordenadores das comunidades são sempre membros das mesmas, com funções de docência e/ou investigação, sendo por isso, em simultâneo, potenciais depositantes dessas mesmas comunidades.

Enc. Bibli: R. Eletr. Bibliotecon. Ci. Inf., Florianópolis, n. esp., $2^{\circ}$ sem. 2010. ISSNe 1518-2924.
} 


\section{DESENHO DO ESTUDO}

\subsection{População inquirida e sujeitos respondentes}

Foram consideradas para efeito deste estudo 33 comunidades do RepositóriUM que se encontravam activas no período de 10 de Fevereiro a 28 de Março de 2010. Não foram consideradas como pertencendo ao universo do estudo as comunidades diretamente ligadas aos Serviços de Documentação da Universidade do Minho, pelo facto de terem uma constituição muito particular, uma vez que uma delas integra os responsáveis pelo RepositóriUM e técnicos dos SDUM, e a uma outra é referente a teses de mestrado e doutoramento da UM, sendo coordenada a partir dos próprios serviços de documentação. Assim, a população de sujeitos deste estudo era constituída por 33 Coordenadores de comunidades do RepositóriUM, tendo os mesmos sido contactados no sentido de procederem ao preenchimento do questionário de recolha de dados.

Os coordenadores foram contactados diretamente pelos SDUM no dia 10 de Fevereiro de 2010, através de uma comunicação via correio electrónico, descrevendo o objectivo da investigação, solicitando a colaboração para responderam ao survey e informando o endereço electrónico do instrumento de recolha de dados. No dia 22 de Fevereiro foi reenviada a partir dos SDUM nova mensagem para todos Coordenadores de comunidades: No dia 8 de Março, procedeu-se a uma última solicitação dirigida aos Coordenadores que, até essa data, ainda não haviam respondido ao questionário.

Apesar dos esforços desenvolvidos, e da colaboração directa dos SDUM neste processo, apenas obtivemos 16 respostas, o que corresponde a uma taxa de retorno de $48 \%$. Todos os questionários foram respondidos pelos próprios coordenadores das comunidades excepto num caso em que o respondente declarou estar a responder por delegação do coordenador.

\subsection{Método de investigação}

Como método de investigação neste estudo, optou-se pela realização de um levantamento (survey) o qual é um método amplamente utilizado nas investigações em ciências sociais aplicadas. Este método permite atingir uma população ou amostra de população valendo-se de questionário ou entrevista, com o fim de levantar as informações necessárias para esclarecer fenómenos ou factos relacionados com a investigação. Envolve a recolha e a quantificação de dados, os quais se tornam fontes permanentes de informação. É uma técnica de grande utilidade em função de sua ampla aplicabilidade.

Segundo Babbie (2005) são três os objetivos gerais que definem o interesse de se utilizar esta técnica de investigação: descrição, explicação e exploração, este último, significando mecanismo de busca, quando se investiga algum tema. Conforme o meio de recolha de dados escolhido, o tipo de survey poderá ser escrito, oral ou eletrónico, auto-administrado ou utilizando a técnica de entrevista. Os instrumentos de recolha de dados auto-administrados são entregues aos respondentes, através do correio tradicional ou eletrónico, acompanhados de uma mensagem explicativa. Após o prazo estabelecido para o seu preenchimento, os dados são recolhidos pela equipe de investigação. 
$\mathrm{O}$ instrumento de recolha de dados usado neste estudo foi um questionário online desenvolvido no sistema SurveyMonkey ${ }^{9}$, sistema de recolha de dados com possibilidade de utilizar links personalizados, múltiplos tipos de questões, múltiplas formas de pesquisa e análise de dados e de tratamento dos mesmos.

Foi realizado durante o mês de janeiro um teste ao questionário desenvolvido através do pedido de análise e preenchimento do mesmo por parte de técnicos e investigadores da UM envolvidos no desenvolvimento do RepositóriUM. De acordo com as observações efectuadas pelos mesmos procedeu-se a reajustes no questionário tendo em vista e elaboração da versão final. A disponibilização do questionário para os coordenadores foi feita online e os contactos com os mesmos efectuados por correio electrónicos e mediados pelos SDUM.

\section{APRESENTAÇÃO E DISCUSSÃO DE RESULTADOS}

\subsection{Caracterização geral dos Coordenadores - experiência no cargo}

De entre as comunidades relativamente às quais obtivemos respostas, verificamos que, de acordo com os dados recolhidos, 53.3\% (8) estão constituídas desde 2004, sendo cinco (5) mais recentes. Em dois casos os coordenadores afirmaram desconhecer a data de criação da comunidade (ver Quadro 2) e houve um coordenador que não respondeu a esta questão.

\begin{tabular}{|r|c|c|}
\hline $\begin{array}{l}\text { Desde quando está constituída a comunidade } \\
\text { pela qual é responsável/coordenador? }\end{array}$ & $\begin{array}{c}\text { Freq. } \\
\text { rel. }\end{array}$ & $\begin{array}{c}\text { Freq. } \\
\text { abs. }\end{array}$ \\
\hline Desconheço & $13.3 \%$ & 2 \\
\hline Desde 2004 & $53.3 \%$ & 8 \\
\hline Desde 2005 & $20.0 \%$ & 3 \\
\hline Desde 2006 & $6.7 \%$ & 1 \\
\hline Desde 2007 & $6.7 \%$ & 1 \\
\hline Desde 2008 & $0 \%$ & 0 \\
\hline Desde 2009 & $0 \%$ & 0 \\
\hline Desde 2010 & $0 \%$ & 0 \\
\hline Total & $100 \%$ & 15 \\
\hline
\end{tabular}

Quadro 2 - Data de criação das comunidades constituintes do RepositóriUM

Fonte: Autores

Um dos aspectos que ressalta das respostas obtidas é o facto de muitos dos respondentes serem coordenadores das comunidades desde a sua criação, $(53.3 \%$ - 8) existindo, contudo casos em que a sua experiência como coordenadores é mais recente (ver Quadro 3).

\footnotetext{
${ }^{9}$ http://pt.surveymonkey.com/

Enc. Bibli: R. Eletr. Bibliotecon. Ci. Inf., Florianópolis, n. esp., 2º sem. 2010. ISSNe 1518-2924.
} 


\begin{tabular}{|r|c|c|}
\hline $\begin{array}{l}\text { Há quanto tempo é responsável/coordenador de } \\
\text { uma das comunidades do RepositóriUM? }\end{array}$ & $\begin{array}{c}\text { Freq. } \\
\text { rel. }\end{array}$ & $\begin{array}{c}\text { Freq. } \\
\text { abs. }\end{array}$ \\
\hline Desde 2004 & $53.3 \%$ & 8 \\
\hline Desde 2005 & $20.0 \%$ & 3 \\
\hline Desde 2006 & $6.7 \%$ & 1 \\
\hline Desde 2007 & $6.7 \%$ & 1 \\
\hline Desde 2008 & $6.7 \%$ & 1 \\
\hline Desde 2009 & $6.7 \%$ & 1 \\
\hline Desde 2010 & $0 \%$ & 0 \\
\hline Total & $100 \%$ & 15 \\
\hline
\end{tabular}

Quadro 3 - Antiguidade dos coordenadores das comunidades do RepositóriUM no cargo.

Fonte: Autores

\subsection{Caracterização dos Coordenadores - actividade enquanto depositantes}

Um dos aspectos sobre os quais inquirimos os coordenadores foi quanto às suas práticas enquanto depositantes, tendo constatado que $56.3 \%$ (9) dos respondentes afirmaram proceder ao auto-arquivamento da sua produção científica "de forma pontual", ou seja, proceder ao auto-arquivamento da sua produção científica esporadicamente. Há mesmo um coordendor que afirma não proceder ao auto-arquivo, tendo ficado por esclarecer as razões para esse facto. Apenas seis dos coordenadores, correspondendo a $37.5 \%$ dos respondentes, respondeu proceder ao auto-depósito de forma sistemática (ver Quadro 6).

\begin{tabular}{|c|c|c|}
\hline $\begin{array}{l}\text { Na sua qualidade de professor(a)/investigador(a), } \\
\text { procede ao auto-arquivamento da sua produção } \\
\text { científica no repositóriUM? }\end{array}$ & Freq. rel. & $\begin{array}{c}\text { Freq. } \\
\text { abs. }\end{array}$ \\
\hline Sim, de forma pontual & $56.3 \%$ & 9 \\
\hline Sim, de forma sistemática & $37.5 \%$ & 6 \\
\hline Não & $6.3 \%$ & 1 \\
\hline Total & $100 \%$ & 16 \\
\hline
\end{tabular}

Quadro 6 - Atitude perante ao auto-arquivamento por parte dos coordenadores de comunidades do RepositóriUM.

Fonte: Autores

Estes dados referentes ao auto-arquivamento por parte dos coordenadores das comunidades não deixam de ser surpreendentes na medida em que consideramos que seria expectável uma atitude mais pró-activa dos coordenadores nesse domínio. Torna-se difícil de entender como coordenadores que não procedem ao auto-arquivamento da sua produção científica, ou o fazem apenas pontualmente, podem motivar e dinamizar outros membros da comunidade a adoptarem essa prática. Importa ter presente que a natureza das questões do questionário de recolha de dados não permitiu recolher informação que possam explicar as razões para este comportamento.

De entre os coordenadores que procedem ao depósito de documentos no RepositóriUM um número significativo (11 - 73.4\%) fá-lo há cinco ou mais anos (ver Quadro 7). 


\begin{tabular}{|r|c|c|}
\hline $\begin{array}{l}\text { Há quanto tempo procede ao depósito/arquivo } \\
\text { de documentos no RepositóriUM? }\end{array}$ & $\begin{array}{c}\text { Freq. } \\
\text { rel. }\end{array}$ & $\begin{array}{c}\text { Freq. } \\
\text { abs. }\end{array}$ \\
\hline Desde 2004 & $46.7 \%$ & 7 \\
\hline Desde 2005 & $26.7 \%$ & 4 \\
\hline Desde 2006 & $13.3 \%$ & 2 \\
\hline Desde 2007 & $6.7 \%$ & 1 \\
\hline Desde 2008 & $6.7 \%$ & 1 \\
\hline Desde 2009 & $0 \%$ & 0 \\
\hline Desde 2010 & $0 \%$ & 0 \\
\hline Total & $100 \%$ & 15 \\
\hline
\end{tabular}

Quadro 7 - Antiguidade dos procedimentos de depósito/arquivo de documentos por parte dos coordenadores de comunidades do RepositóriUM.

Fonte: Autores

Um dos aspectos que nos pareceu relevante considerar relativamente ao perfil dos coordenadores enquanto depositantes, foi a perceção dos mesmos quanto às vantagens percepcionadas relativamente à disponibilização da sua própria produção científica no RepositóriUM. Nesse sentido solicitou-se que assinalassem, de entre um conjunto de alternativas quais as potenciais vantagens dos repositórios, um máximo de três opções que considerassem relevantes. Os dados recolhidos estão sistematizados no Quadro 8.

\begin{tabular}{|c|c|c|}
\hline $\begin{array}{l}\text { Na sua qualidade de professor/investigador que } \\
\text { vantagens percepciona estarem associadas ao } \\
\text { facto de disponibilizar a sua produção científica } \\
\text { no RepositóriUM? }\end{array}$ & $\begin{array}{l}\text { Freq. } \\
\text { rel. }\end{array}$ & $\begin{array}{l}\text { Freq. } \\
\text { abs. }\end{array}$ \\
\hline Maior divulgação da sua actividade de investigação & $100 \%$ & 16 \\
\hline $\begin{array}{l}\text { Maior facilidade de acesso à sua publicação } \\
\text { científica por parte de colegas de outras instituições }\end{array}$ & $93.8 \%$ & 15 \\
\hline $\begin{array}{r}\text { Maior facilidade de acesso à sua publicação } \\
\text { científica por parte dos seus alunos }\end{array}$ & $37.5 \%$ & 6 \\
\hline $\begin{array}{r}\text { Maior probabilidade de ser conhecido e de } \\
\text { estabelecer contacto com outros colegas }\end{array}$ & $50.0 \%$ & 8 \\
\hline $\begin{array}{r}\text { Maior reconhecimento profissional por parte da } \\
\text { comunidade académica e científica }\end{array}$ & $31.3 \%$ & 5 \\
\hline $\begin{array}{r}\text { Não tenho a percepção de existirem vantagens } \\
\text { relevantes }\end{array}$ & $0 \%$ & 0 \\
\hline Outra (refira qual) & $0 \%$ & 0 \\
\hline Total & $100 \%$ & 16 \\
\hline
\end{tabular}

Quadro 8 - Percepção das vantagens associadas ao depósito no RepositóriUM.

Fonte: Autores

A análise dos dados do Quadro 8 revela que todos os sujeitos reconhecem a existência de vantagens na disponibilização da sua produção científica pois nenhum assinalou a opção "não tenho a percepção de existirem vantagens relevantes". Todos os sujeitos referem como vantagem a "maior divulgação da sua actividade de investigação" e 15 de entre os 16 indicam também a "maior facilidade de acesso à sua publicação científica por parte de colegas de outras instituições". Menor número de respondentes assinala a opção "maior facilidade de Enc. Bibli: R. Eletr. Bibliotecon. Ci. Inf., Florianópolis, n. esp., 2º sem. 2010. ISSNe 1518-2924. 
acesso à sua publicação científica por parte dos seus alunos". Contudo, este é também um aspecto percepcionado como uma vantagem do depósito em RI como ressalta não apenas dos dados do Quadro 8 mas também do facto de 62.5\% (10) dos respondentes referirem que "indicam frequentemente o RepositóriUM como um recurso útil aos alunos" e 25\% (4) referirem fazê-lo pontualmente como se verifica da leitura dos dados do Quadro 9.

\begin{tabular}{|c|c|c|}
\hline Indica o RepositoriUM aos seus alunos? & $\begin{array}{c}\text { Freq. } \\
\text { rel. }\end{array}$ & $\begin{array}{c}\text { Freq. } \\
\text { abs. }\end{array}$ \\
\hline $\begin{array}{r}\text { Sim, indico frequentemente o RepositóriUM como } \\
\text { um recurso útil }\end{array}$ & $62.5 \%$ & 10 \\
\hline Sim, mas apenas o faço pontualmente & $25.0 \%$ & 4 \\
\hline Não costumo fazer referência ao RepositóriUM & $12.5 \%$ & 2 \\
\hline $\begin{array}{ll} & \text { Total }\end{array}$ & $100 \%$ & 16 \\
\hline
\end{tabular}

Quadro 9 - Indicação do RepositóriUM aos alunos por parte dos coordenadores de comunidades do RepositóriUM.

Fonte: Autores

Sendo os repositórios institucionais um dos instrumentos privilegiados para a promoção do movimento do acesso livre no sentido de apoiarem a divulgação e o acesso sem custos à produção científica e académica, muitas vezes financiada com fundos públicos, inquirimos os coordenadores sobre o seu conhecimento relativamente aos princípios subjacentes ao movimento do acesso livre (ver Quadro 10). De acordo com as respostas obtidas podemos constatar que três dos coordenadores, correspondendo a $18.8 \%$ dos respondentes, não conhecem os princípios subjacentes ao movimento do acesso livre.

\begin{tabular}{|r|c|c|}
\hline $\begin{array}{l}\text { Tem conhecimento dos princípios do Movimento } \\
\text { do Acesso Livre em prol da divulgação da } \\
\text { produção científica? }\end{array}$ & $\begin{array}{c}\text { Freq. } \\
\text { rel. }\end{array}$ & $\begin{array}{c}\text { Freq. } \\
\text { abs. }\end{array}$ \\
\hline Sim & $81.3 \%$ & 13 \\
\hline Não & $18.8 \%$ & 3 \\
\hline
\end{tabular}

Quadro 10 - Conhecimento dos princípios do movimento do acesso livre por parte dos Coordenadores de comunidades do RepositóriUM.

Fonte: Pesquisa dos autores

Os treze (13) Coordenadores que afirmam conhecer os princípios subjacentes ao OAM, quando questionados sobre as suas fontes de informação relativamente a este assunto, referem a Universidade do Minho, seguida da leitura de artigos científicos sobre o tema (ver Quadro 11), e da participação em eventos científicos. Um dos respondentes indica "outra fonte" de informação, acrescentando ter um conhecimento "vago" decorrente do acesso a artigos disponíveis dessa forma. 


\begin{tabular}{|r|c|c|}
\hline Como tomou conhecimento desse movimento? & $\begin{array}{c}\text { Freq. } \\
\text { rel. }\end{array}$ & $\begin{array}{c}\text { Freq. } \\
\text { abs. }\end{array}$ \\
\hline Através da Universidade do Minho & $66.7 \%$ & 8 \\
\hline Leitura de artigos científicos sobre o tema & $50.0 \%$ & 6 \\
\hline Participação em seminários, simpósios, congressos & $25.0 \%$ & 3 \\
\hline Outra fonte & $8.3 \%$ & 1 \\
\hline Total & $100 \%$ & 12 \\
\hline
\end{tabular}

Quadro 11 - Fonte de informação sobre o movimento do acesso livre.

Fonte: Pesquisa dos autores

O facto de nem todos os Coordenadores de comunidades do RepositóriUM conhecerem os princípios e objectivos do OAM, nos quais se enquadram também os princípios subjacentes à criação de RI, foi de algum modo surpreendente para nós pois consideramos que seria expectável que todos os Coordenadores conhecessem os princípios e objectivos do OAM, nos quais se enquadram também os princípios subjacentes à criação de RI.

\subsection{Políticas de estímulo ao depósito ao nível das comunidades}

Um dos objectivos deste estudo visava identificar, junto dos coordenadores das comunidades, a existência de políticas de estímulo ao depósito, definidas ao nível da cada comunidade. A análise do Quadro 4 evidencia que 62.5\% (10) das comunidades, considerando os dados recolhidos, não possui uma política específica de estímulo ao depósito, para além daquela que é a política institucional geral.

\begin{tabular}{|l|r|c|}
\hline $\begin{array}{l}\text { A comunidade do RepositóriUM pela qual é } \\
\text { responsável/coordenador tem alguma política específica de estímulo } \\
\text { ao depósito? }\end{array}$ & $\begin{array}{c}\text { Freq. } \\
\text { Rel. }\end{array}$ & $\begin{array}{c}\text { Freq. } \\
\text { abs. }\end{array}$ \\
\hline Sim & $37.5 \%$ & 6 \\
\hline Não & $62.5 \%$ & 10 \\
\hline Total & $100 \%$ & 16 \\
\hline
\end{tabular}

Quadro 4 - Existência de políticas de estímulo ao depósito ao nível das comunidades do RepositóriUM.

Fonte: Autores

Entre as seis comunidades, correspondendo a $37.5 \%$ dos respondentes que possuem iniciativas de estímulo ao depósito, encontram-se várias medidas nesse sentido, que se apresentam no Quadro 5.

\begin{tabular}{|r|c|c|}
\hline Iniciativas de apoio/estímulo ao depósito: & $\begin{array}{c}\text { Freq. } \\
\text { rel. }\end{array}$ & $\begin{array}{c}\text { Freq. } \\
\text { abs. }\end{array}$ \\
\hline Apoio à digitalização de documentos & $16.7 \%$ & 1 \\
\hline $\begin{array}{r}\text { Apoio no preenchimento do formulário de depósito } \\
\text { de documentos (depósito-mediado) }\end{array}$ & $50.0 \%$ & 3 \\
\hline Obrigatoriedade de depósito & $83.3 \%$ & 5 \\
\hline $\begin{array}{r}\text { Valorização curricular (ou outra) das publicações } \\
\text { que tenham sido colocadas no repositório }\end{array}$ & $0 \%$ & 0 \\
\hline Total & $100 \%$ & 6 \\
\hline
\end{tabular}

Quadro 5 - Tipo de iniciativas de estímulo ao depósito ao nível das comunidades do RepositóriUM. Fonte: Autores 
De entre as iniciativas de estímulo ao depósito, adotadas pelas seis comunidades em causa, a mais comum, referida por cinco dos seis respondentes é a da "obrigatoriedade" do depósito, sendo que três indicam também o apoio ao preenchimento do formulário de depósito, ou seja, a adopção de uma prática que podemos designar de depósito-mediado, e um refere o apoio à digitalização de documentos. Nenhum dos respondentes assinalou a opção de resposta "Valorização curricular (ou outra) das publicações que tenham sido colocadas no repositório" nem referiram outras iniciativas para além das indicadas, apesar de terem essa oportunidade durante o preenchimento do questionário.

\section{CONCLUSÃO E REFLEXÕES FINAIS}

A análise dos dados recolhidos sugerem-nos um conjunto de reflexões que entendemos poderem ser aplicadas ao caso do RepositóriUM mas também constituir uma orientação para outros RI em desenvolvimento.

Todos os coordenadores valorizam o potencial do repositório na divulgação da sua produção académica e científica e metade dos respondentes refere também o potencial do depósito no RI como forma de terem mais probabilidades de serem mais conhecidos e de estabelecerem contactos com outros colegas. Seis dos respondentes $(40 \%)$ referem também a maior facilidade de acesso dos seus alunos à sua produção académica e científica como uma vantagem do RepositóriUM.

Apesar do reconhecimento de vantagens associadas ao depósito no RepositóriUM e de 73.3\% dos coordenadores de comunidades desempenharem essa função há cinco (5) ou mais anos, nem todos conhecem aspectos que consideramos importantes, como sejam os princípios do Movimento do Acesso Livre e apenas 37.5\% (6) refere fazer o auto-arquivamento da sua própria produção académica e científica de forma sistemática. Estes dados apontam, no nosso entender, para a necessidade de se reflectir sobre o perfil, as funções e a formação dos Coordenadores das comunidades no sentido destes poderem desempenhar um papel mais activo e interveniente na dinamização das comunidades e dos membros que as integram.

No que se refere às políticas de estímulo ao auto-arquivamento definidas ao nível das Comunidades estas existem apenas em 6 das comunidades em causa e centram-se essencialmente no "depósito-mediado" e no estabelecimento de uma "obrigatoriedade nesse depósito."

O conjunto de dados recolhidos permite-nos apresentar algumas sugestões que pensamos poderem valorizar e reforçar o papel dos coordenadores de comunidades em prol da divulgação dos princípios do $\mathrm{OA}$ e de uma maior actividade ao nível da mobilização e dinamização das diferentes comunidades. Assim, concluímos sugerindo algumas iniciativas que talvez possam ajudar a atingir este desiderato:

a) Definir um perfil de competências e motivações para potenciais coordenadores/dinamizadores de comunidades;

b) Clarificar explicitamente, eventualmente ao nível global da Universidade, as funções a desempenhar pelos Coordenadores;

c) Reconhecer e valorizar institucionalmente o papel que os Coordenadores podem desempenhar na dinamização das Comunidades e do RepositoriUM; 
d) Promover a formação inicial e periódica de coordenadores/dinamizadores de comunidades, nomeadamente no que se refere: 1) às funcionalidades disponíveis no repositório, 2) aos princípios do Open Acess e aos 3) objectivos dos repositórios institucionais;

e) Promover encontros de coordenadores/responsáveis por comunidades de modo a partilharem experiências de motivação/incentivo ao depósito.

No caso concreto do estudo que apresentamos, consideramos que o mesmo deverá ser complementado através de um conjunto de entrevistas que enriqueçam a informação recolhida.

Esperamos que este estudo sirva de base e de estímulo para a realização de estudo similar, relativa a outros repositórios e, que possibilitem uma análise comparativa entre políticas de dinamização de comunidades, contribuindo desse modo para o alargamento da base de conhecimentos nesse domínio e para a definição de um conjunto de princípios que se revelem constituintes de "boas práticas" neste domínio.

\section{REFERÊNCIAS}

BABBIE, Earl. Métodos de pesquisa de survey. Belo Horizonte: Editora da UFMG, 2005.

BARRETO, Aldo de Albuquerque. Mudança estrutural no fluxo do conhecimento: a comunicação eletrônica. Revista Ciência da Informação, Brasília, DF, v. 27, n. 02, p. $122-$ 126, 1998. Disponível em: http://www.scielo.br/pdf/ci/v27n2/barreto.pdf. Acesso em: jan. 2006.

BRICENO, Y et al. Institutional Repository saber.ula.ve: A testimonial perspective. In: International Conference on Open Access, Accra Ghana, Ghana, 2009. Disponível em: http://arxiv.org/ftp/arxiv/papers/0912/0912.2032.pdf. Acesso em: 23 mar. 2010.

COSTA, Sely M. S. Filosofia aberta, modelos de negócios e agências de fomento: elementos essenciais a uma discussão sobre o acesso aberto à informação científica. Ciência da Informação, v. 35, n. 2, maio/ago. 2006. Disponível em: http://revista.ibict.br/index.php/ciinf/article/viewFile/827/670. Acesso em 22 mar. 2007

CROW, R. The case for institutional repositories: a SPARC position paper. [S.1.]: The Scholarly Publishing and Academic Resources Coalition, 2002. 37 p. Disponível em: http://www.arl.org/sparc/IR/ir.html. Acesso em: 10 mar. 2006.

DAVILA, Jacinto A, NUNEZ, Luis A, SANDIA, Beatriz et al. www.saber.ula.ve: un ejemplo de repositorio institucional universitario. INCI. [online]. v. 31, n.1, ene. 2006, p. 29-36. Disponível em: http://www.scielo.org.ve/scielo.php?script=sci arttext\&pid=S0378-

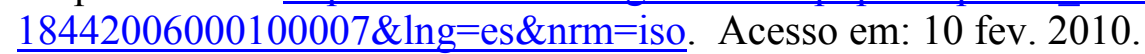

FERREIRA, Miguel; RODRIGUES, Eloy; BAPTISTA, Ana Alice, SARAIVA, Ricardo (2008). Carrots and Sticks - Some Ideas on How to Create a Successful Instituional Repository. D-Lib Magazine, v. 14. n. 1/2, January/February 2008. Disponível em http://www.dlib.org/dlib/january08/ferreira/01ferreira.html Acesso em 12.05.2010. 
JORGE, Ricardo Arencibia. Las iniciativas para el acceso abierto a la información científica en el contexto de la Web semântica. Biblos. v. 7, n. 25/26, jul-dic 2006.

Disponível em: http://dialnet.unirioja.es/servlet/articulo?codigo=2170710. Acesso em: 4 jan. 2009.

KING, Donald W. An approach to open access author payment. D-LIB Magazine. v. 16, n. 3/4, mar-apr 2010.

Disponível em: http://www.dlib.org/dlib/march10/king/03king.print.html. Acesso em: 18 mar. 2010.

LYNCH, Clifford. Institutional Repositories: Essential Infrastructure for Scholarship in the Digital Age. En ARL Bimonthly Report, 2003, n. 226. Disponível em: http://www.arl.org/newsltr/226/ir.html. Acesso em: 23 out 2003.

MARCONDES, Carlos Henrique; SAYÃO, Luis Fernando. Documentos digitais e novas formas de cooperação entre sistemas de informação em C \& T. Ciência da Informação, Brasília, v. 31, n. 3, p. 42-54, 2002. Disponível em:

http://www.scielo.br/pdf/ci/v31n3/a05v31n3.pdf. Acesso em: 21.05.2005.

MARCONDES, Carlos Henrique. O acesso livre na informação científica e tecnológica. IN: FUNDAÇÃO OSWALDO CRUZ. Instituto de Comunicação e Informação Científica e Tecnológica em Saúde. Seminário SUS 20 anos: desafios para a informação e comunicação em Saúde. Rio de Janeiro: Fio Cruz- ICICT, 2009. Disponível em:

http://www.fiocruz.br/cict/media/susrevisado.pdf. Acesso em: 20 out. 2009

OPPER, K. R. Conhecimento objetivo: uma abordagem evolucionária. São Paulo: USP,1975. . Conjecturas e refutações. Brasília: UnB, 1972.

SOUSA, Carla; QUONIAM, Luc; TRIGO, Miguel. Ferramenta de gestão do conhecimento: $o$ caso B-Digital. 2008. Disponível em:

https://bdigital.ufp.pt/dspace/bitstream/10284/919/3/306-317.pdf Acesso em: 18 mar. 2010.

STUMPF, Ida Regina Chitto. Passado e futuro das revistas científicas. Ciência da Informação, Brasília, v. 25, n. 3, 1996. Disponível em:

http://www.ibict.br/cienciadainformacao/includtdoc.php?id=846\&article=504\&mode=pdf. Acesso em: 21.05.2005.

RODRIGUES, Eloy. Implantação do Repositório Institucional da Universidade do Minho, 2010. Entrevista semi-estruturada concedida a Flavia Garcia Rosa, no SDUM, Braga, Portugal, em 11 de janeiro de 2010.

RODRIGUES, Eloy et al. RepositóriUM : criação e desenvolvimento do Repositório Institucional da Universidade do Minho. In: CONGRESSO NACIONAL DE BIBLIOTECÁRIOS, ARQUIVISTAS E DOCUMENTALISTAS, 8, Estoril, 2004. Nas encruzilhadas da informação e da cultura : (re)inventar a profissão, Actas...[CD-ROM]. Lisboa : Associação Portuguesa de Bibliotecários, Arquivistas e Documentalistas, 2004. 


\begin{abstract}
The Open Access Movement (OAM) was stimulated by two important events: the development of Information and Communication Technologiess which facilitate the dissemination of and accessibility to information, and the high charges by large publishers who controlled the market for scientific publications. The Institutional Repositories (IR) are a main and growing element of the OAM. The RepositórioUM of Universidade do Minho is the reference for this study which is part of a larger project related to IR at the Universidade Federal da Bahia, Brazil. The focus of this stage are 33 coordinators of the RepositórioUM`s communities. The method used for the development of this work was a survey, using a data-gathering instrument made available online by SurveyMonkey, sent to each coordinator. The analysis of the data collected suggests a set of reflections that we believe can be applied not only to the case of RepositóriUM but also to provide guidance to other developing IR. The policy established by the institution is a guide for other communities. The advantages of deposit are recognized by most surveyees; one advantage being the easier access enabled to colleagues and students as well as the indication for RI students. Some measures to enhance the role of coordinators are suggested in this paper.
\end{abstract}

KEYWORDS: Institutional repositories. RepositóriUM. Free access. Scholarly journals. Scientific publications.

Originais recebidos em: 30/03/2010

Aceito para publicação em: 29/09/2010 